\title{
Simulation of currents, ice melting, and vertical mixing in the Barents Sea using a 3-D baroclinic model
}

\author{
KJELL STØLE-HANSEN and DAG SLAGSTAD
}

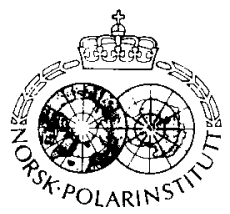

\begin{abstract}
Støle-Hansen, K. \& Slagstad, D. 1991: Simulation of currents, ice melting, and vertical mixing in the Barents Sca using a 3-D baroclinic model. Pp. 33-44 in Sakshaug. E. Hopkins. C. C. E. \& Øritsland, N. A. (cds.): Proceedings of the Pro Mare Symposium on Polar Marine Ecology. Trondheim, 12-16 May 1990. Polar Research I0(1).
\end{abstract}

A baroclinic. 3-D model is described. It is adapted to the Barents Sea and includes thermodynamics and atmospheric input. The freczing and melting of ice is allowed for in the model. The main task of the study is to look at the development of the ice cover, the vertical mixing. and the vertical and horizontal density gradients.

Despite simple approximations in the air temperature input, realistic ice-cover is produced in the modcl area during simulation of a "freezing period" (winter). This intermediate result is briefly discussed and also forms the start of a "melting period" simulation (spring/summer). Atmospheric input data (wind, air pressure, and heat flux) from the spring and summer 1983 is used, and details about vertical mixing. temperature. and salinity are discussed. The simulation results demonstrate the temporal variation of the thermocline depth, the variation of the ice cover. and the horizontal changes of density. The conclusion is that despite often simplified input, the model seems to produce a physical picture characteristic of the Barents Sea.

Kjell Støle-Hansen and Dag Slagstad, SINTEF Automatic Control, N-7034 Trondheim. Norway (revised February 1991).

\section{Introduction}

The general feature of the circulation pattern in the Barents Sea is well known through hydrographical studies combined with a few current measurements (Tansiura 1959; Midttun \& Loeng 1987; Loeng 1989). Mathematical models have been applied for the area during the last 2-3 years; Ådlandsvik (1989) used a wind-driven model to study variable Atlantic inflow to the Barents Sea. Three-dimensional density-driven currents have been studied by means of a baroclinic model by Slagstad et al. (1989). The Barents Sea is characterised by relatively great vertical and horizontal density gradients, which are closely related to the processes of freezing and melting of the ice and freshwater input from land. These gradients imply that a hydrodynamic mathematical model of the area should be baroclinic. Running the model with no density gradients confirms this suggestion as the current pattern became very different from the observed pattern (Slagstad 1987). Most of the Barents Sea has been covered by systematic field observations from ships in the autumn during the annual larval survey performed by the Institute of Marine Research (IMR) in Bergen. During the spring, which is the most important period for primary and secondary production, density data are only available from the southern part. The aim of this work is therefore to use the measured density distribution from the autumn as an initial field and create the vertical and horizontal distribution of temperature. salinity, and ice for the spring and early summer season. These seasonal fields will make it possible to simulate the vertical eddy diffusion coefficients which are important for algal growth. The intention is not to exactly recreate the physical fields from the period we were simulating, but rather to study the principles of how atmospheric input affects the dynamics of freezing and melting ice, and the formation of vertical density gradients.

\section{Model description}

The model described is a 3-dimensional, baroclinic, finite-difference "level model" that is defined by a sequence of fixed but permeable levels. Each level has a fixed thickness, except the level near the surface and the one next to the bottom. Thus, the number of levels will be a function of the horizontal coordinates. 


\section{Basic equations}

The equations describing motion of incompressible water on a rotating earth, incorporating the horizontal and vertical diffusion of momentum, can be written as follows:

Velocity in $\mathrm{x}$-direction:

$$
\begin{aligned}
\frac{\partial u}{\partial t}=f v-u \frac{\partial u}{\partial x}- & v \frac{\partial u}{\partial y}-w \frac{\partial u}{\partial z} \\
& -\frac{1}{\rho} \frac{\partial p}{\partial x}+A_{v} \nabla^{2} u+\frac{\partial}{\partial z} A_{v} \frac{\partial u}{\partial z}
\end{aligned}
$$

Velocity in y-direction:

$$
\begin{aligned}
\frac{\partial v}{\partial t}=-f u-u \frac{\partial v}{\partial x} & -v \frac{\partial v}{\partial y}-w \frac{\partial v}{\partial z} \\
& -\frac{1}{\rho} \frac{\partial p}{\partial y}+A_{h} \nabla^{2} v+\frac{\partial}{\partial z} A_{v} \frac{\partial v}{\partial z}
\end{aligned}
$$

Vertical velocity is found from the equation of continuity:

$\frac{\partial w}{\partial z}+\frac{\partial u}{\partial x}+\frac{\partial v}{\partial y}=0$

and surface elevation:

$\eta=\int w_{1} d t$

where

$u, v$ - horizontal velocity components in $x$ - and $y$ directions, respectively

w - vertical velocity component

$\mathbf{w}_{1}$ - vertical velocity of surface elevation, i.e. upper layer

$h$ - height of the free surface from the undisturbed mean

f - Coriolis parameter

$\rho$ - density

$A_{h}$ - horizontal eddy diffusion of momentum

$A_{1}$ - vertical eddy diffusion of momentum

$\mathrm{p}$ - pressure found by the equation

$p=\int_{z}^{\eta} \rho g d z+P a$

where $\mathrm{Pa}$ is the atmospheric pressure.

The space-time variations of water density, $\rho$, are found by the functional relationship

$\rho=\rho(S, T)$ where $S$ and $T$ are the salinity and temperature of the water. These scalar fields can be modelled by a balance equation of the form:

$$
\begin{aligned}
\frac{\partial c}{\partial t}=-\frac{\partial}{\partial x}(u c)-\frac{\partial}{\partial y}(v c)-\frac{\partial}{\partial z}(w c) \\
+K_{h} \nabla^{2} c+\frac{\partial}{\partial z}\left(K_{v} \frac{\partial c}{\partial z}\right)+\delta_{c}
\end{aligned}
$$

where

c $-\mathrm{S}$ or $\mathrm{T}$

$\mathrm{K}_{\mathrm{h}}$ - horizontal diffusion

$K_{v}$ - vertical diffusion

$\delta_{c}-c=T$ : thermodynamic interaction between the upper layer and the atmosphere $c=S$ : supply of saline water or freshwater during freezing or melt, respectively,

and the operator $\nabla^{2}$ means

$\nabla^{2} \Theta=\frac{\partial^{2} \Theta}{\partial x^{2}}+\frac{\partial^{2} \Theta}{\partial y^{2}}$

and $\Theta$ is any function of $x$ and $y$.

\section{Vertical mixing}

The vertical eddy diffusion coefficient, $A_{v}$, is calculated as a function of Richardson's number $(\mathrm{Ri})$ and the density $(\rho)$ gradient. The formula is an extension of the one used in Slagstad (1987). The "switching"-coefficient $\alpha$ is dimensioned through inspiration from Price \& Weller (1986), and the constants $0.01,100.0$ and 500.0 are based on a comparison of simulated and observed current profiles in the Barents Sea. The following relationship is assumed:

$A_{\mathrm{v}}=(0.01+100.0 \times \alpha+500.0 \times \beta) 10^{-4}$

where

$\alpha= \begin{cases}1 \mathrm{Ri}<0.65 \\ 0 \mathrm{Ri}>0.65\end{cases}$

$\beta=\left\{\begin{array}{l}1 \frac{d \rho}{d z}<0 \\ 0 \frac{d \rho}{d z}>0\end{array}\right.$

$R i=$ Richardson's number $=\frac{g \times \frac{d \rho}{d z}}{\rho \times\left(\frac{d u}{d z}\right)^{2}}$

$\rho=$ density

$\mathrm{u}=$ current velocity vector. 
Even though the vertical eddy diffusion coefficient is improved compared to Slagstad (1987), it is still a simple formulation and it is quite clear that it could have been more advanced. It is likely that one of the "turbulent closure" formulations for the vertical eddy diffusion, reviewed by Rodi (1987), would improve this part of the model.

\section{Numerics and boundary conditions}

The equations of momentum and continuity are solved using a finite difference technique similar to that of Tinglee et al. (1979). The state variables are made discrete in space on a staggered grid known as the Arakawa $\mathrm{C}$ grid (Mesinger \& Arakawa 1976). Central differentiating is used in space whereas a two-level, semi-implicit scheme is used in time. The non-linear terms are implemented by a hybrid scheme combining central- and upstream differentiating. The advection of temperature and salt is approximated by a second order upstream scheme. Details of the numerics (non-linear terms, set up for the level model and so on) may be found in Slagstad et al. (1989).

The Orlanski version of Sommerfeldt's radiation condition (Orlanski 1976) is used as the open boundaries. In addition, the surface elevation is adjusted at the northern open boundary to match the observed or calculated average inflow and outflow (Blindheim 1989; Aagaard et al. 1983). This means an outflow of about $2.0 \mathrm{~Sv}$ between Frans Josef Land and Novaja Zemlja, and a 'weak' $\left(0.01-0.02 \mathrm{~ms}^{-1}\right)$ inflow of surface water between Nordaustlandet and Frans Josef Land. This is done over a long time scale and does not influence the waves passing through the boundary. In the south, a constant input velocity profile is applied: $0.1 \mathrm{~ms}^{-1}$ for the Norwegian Atlantic Current and $0.25 \mathrm{~ms}^{-1}$ for the Norwegian Coastal Current.

\section{Mode splitting}

In order to increase computer efficiency a mode splitting technique is used. This is similar to the one described by Berntsen et al. (1981). The horizontal velocity vector $\mathrm{v}$ is decomposed into the vertical average value $\mathrm{V}$ and a deviation from the mean value $v$ :

$v=V+v$ and $V=\frac{1}{H} \int_{-h}^{\eta} v d z$

where $\mathrm{H}=\mathrm{h}+\eta$.
A complete description is found in Berntsen et al. (1981). The finite differentiating technique (Slagstad 1987) varies, however, from their leapfrog scheme.

\section{Thermodynamics and ice}

The flux of energy from the atmosphere to the surface water mainly consists of four elements (Pollard et al. 1983):

Energy flux $=\mathrm{Fh}+\mathrm{Fe}+\mathrm{Fi}+\mathrm{Fq}$

where (index 10 referes to a height 10 metres above the sea surface):

$\begin{array}{ll}\text { Fh (sensible heat) } & : F h\left(T, T_{10}, V_{10}\right) \\ \text { Fe (latent heat) } & : F e\left(q, q_{10}\right) \\ F i \text { (infrared flux) } & : F i\left(f_{c}, T^{4}\right) \\ F q \text { (solar radiation) } & : \text { is measured }\end{array}$

and

T - surface water temperature,

$\mathrm{T}_{10}$ - air temperature,

$\mathrm{V}_{10}$ - wind speed,

$\mathrm{q}_{10}$ - specific humidity of air,

$q$ - saturation specific humidity of air at the water surface and

$f_{c}$ - cloud cover factor.

Exactly how these fluxes are computed is given in Pollard et al. (1983) and Slagstad (1987).

Depending on the sign of the energy flux and the water temperature, freezing or melting processes will take place. The ice model and the processes related to freezing and melting of ice are described by Slagstad (1987).

\section{Ice transport}

The transport of ice is not a trivial problem. The ice is not homogeneous and it may be firmly attached to land or other ice masses. Ideally, acceleration of ice is a result of several forces such as drag from wind and water, the Coriolis force, and gravity due to the sea surface slope. The drag from wind and water is proportional to the area of the ice, and independent of its thickness. Thus, when the ice cover is thin and there are strong wind or water forces, the acceleration may become quite high. Using this method to simulate ice transport would require such a small time step that the ice model alone would take a large proportion of the total computer resources. We 
therefore neglected the dynamics of the ice transport and calculated the stationary velocities of ice as a function of wind and current speed. The wind component is computed in accordance with "Zubov's rule" (i.e. the wind-induced ice velocity is $2 \%$ of the wind speed and is directed $28^{\circ}$ to the right of the wind direction. Zubov (1945)). The net ice velocity is then

$V_{i}=V_{c}+V_{z}$

where

$V_{1}$ - the ice velocity vector.

$V_{c}$ - the current velocity vector and,

$\mathrm{V}_{\mathrm{z}}$ - the wind-induced velocity vector calculated from the experimental "Zubov's rule".

The validity of this formula (equation 15) is of course limited, but in the open sea it will probably give a good approximation. As will be shown below, the quality of the atmospheric input data (air temperature, humidity, and solar radiation) is poor, and a more sophisticated ice model will only improve our calculations if the quality of the input data is improved simultaneously. It is obvious that the ice transport (including the atmospheric input and the rest of the ice model) should be one of the most relevant areas for

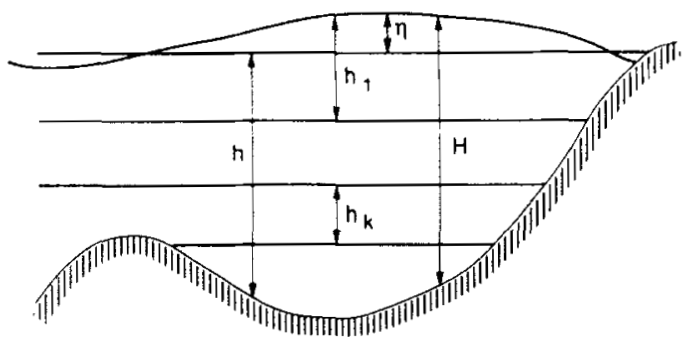

Fig. 1. The level model. $\mathrm{H}=$ the total water depth. $\mathrm{h}=$ the height of the undisturbed mean. $h_{k}=$ the thickness of level number $k, \eta=$ the height of free surface from $h$.

improvements in a next version of this model. Hibler (1979) is one of several researchers who have made contributions to ice modelling.

\section{Model set up}

The present version of the model has twelve levels $(5 \times 10,20,30.2 \times 50$ and $3 \times 100 \mathrm{~m})$. The horizontal grid point distance is $20 \mathrm{~km}$, and the model area is covered by $80 \times 70$ horizontal grid points. The levels of the model are visualised in Fig. 1 and the model area with bottom topography is shown in Fig. 2.

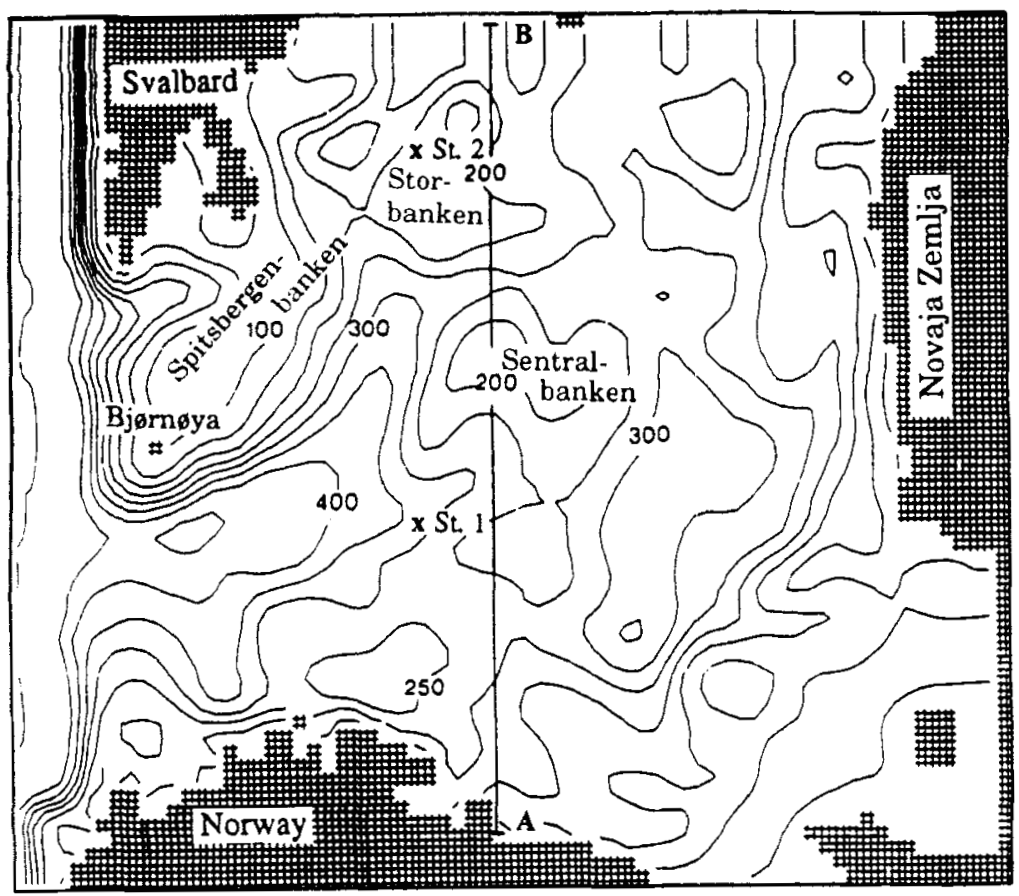

Fig. 2. Bottom topography of the model area. An isobath is shown for every $50 \mathrm{~m}$. 


\section{Input to the model}

Besides the initial fields of temperature and salinity, the model should allow for (and is also capable of handling) continuous updating of the atmospheric input. A common problem for the mathematical models is access to a complete set of realistic input data. This is also true for the present model. The density field is interpolated from a data set from 590 hydrographical stations from the Barents Sea, obtained by the Institute of Marine Research during the autumn of 1988. This density field was used without any atmospheric input to simulate a steady state current field (Fig. 3; from Slagstad et al. 1989). We will later use both the density field and the current field as initial values for the "freezing period".

Simulated wind and pressure fields were obtained every six hours for the whole model domain from the Norwegian Meteorological Institute (MI). Air temperature, solar radiation, and relative humidity were registered at Bjørnøya $\left(74.3^{\circ} \mathrm{N}, 19.0^{\circ} \mathrm{E}\right.$; see Fig. 2). As the meteorological conditions in other parts of the model domain (up to $1,200 \mathrm{~km}$ from Bjørnøya) are different, a more realistic set of input data was obtained by making some assumptions about the geographical distribution of the single point data:

1. The "winter" temperature field decreases linearly from the $\mathrm{Bj} \emptyset \mathrm{rn} \emptyset \mathrm{ya}$ value by $10^{\circ} \mathrm{C}$ towards the north-east border. The summer temperature field only decreases by $3^{\circ} \mathrm{C}$. Equivalent relations are applied to the south and west and result in a temperature field with reference to the measured Bjørnøya temperature. The temperature distributions are obtained by studying an atlas of the mean seasonal air temperature in the area.

2. The measured solar radiation at Bjørnøya is compared to the theoretical formula of solar radiation, and a mean value of cloud cover is calculated each day. This mean value is applied together with the theoretical formula to calculate the solar radiation in the whole model domain, such that the cloud cover will vary in the same manner as at Bjørnøya (which has a correct value).
Fig. 3. Initial density-driven surface currents based on 590 hydrographical stations logged in the autumn 1988 (Slagstad et al. 1989). Velocities less than $1 \mathrm{~cm} \mathrm{~s}^{-1}$ are indicated by a dot.

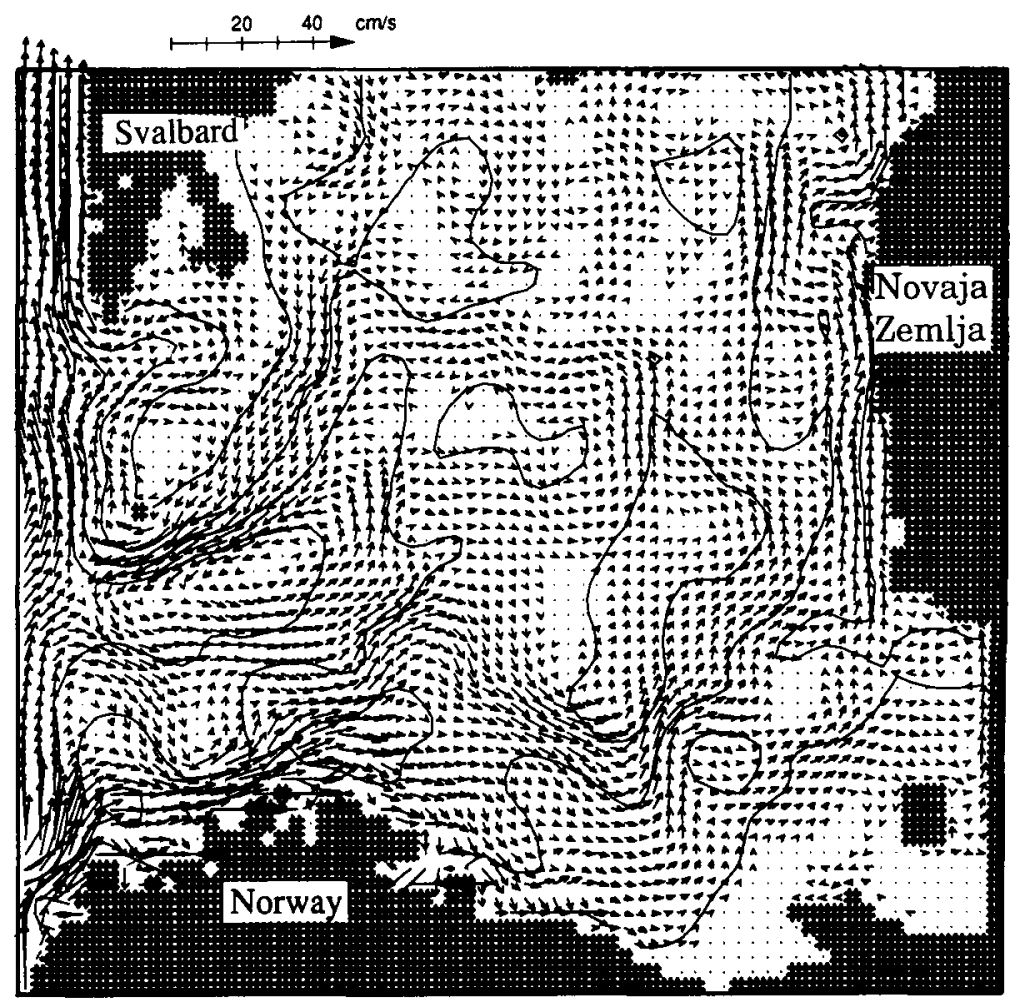




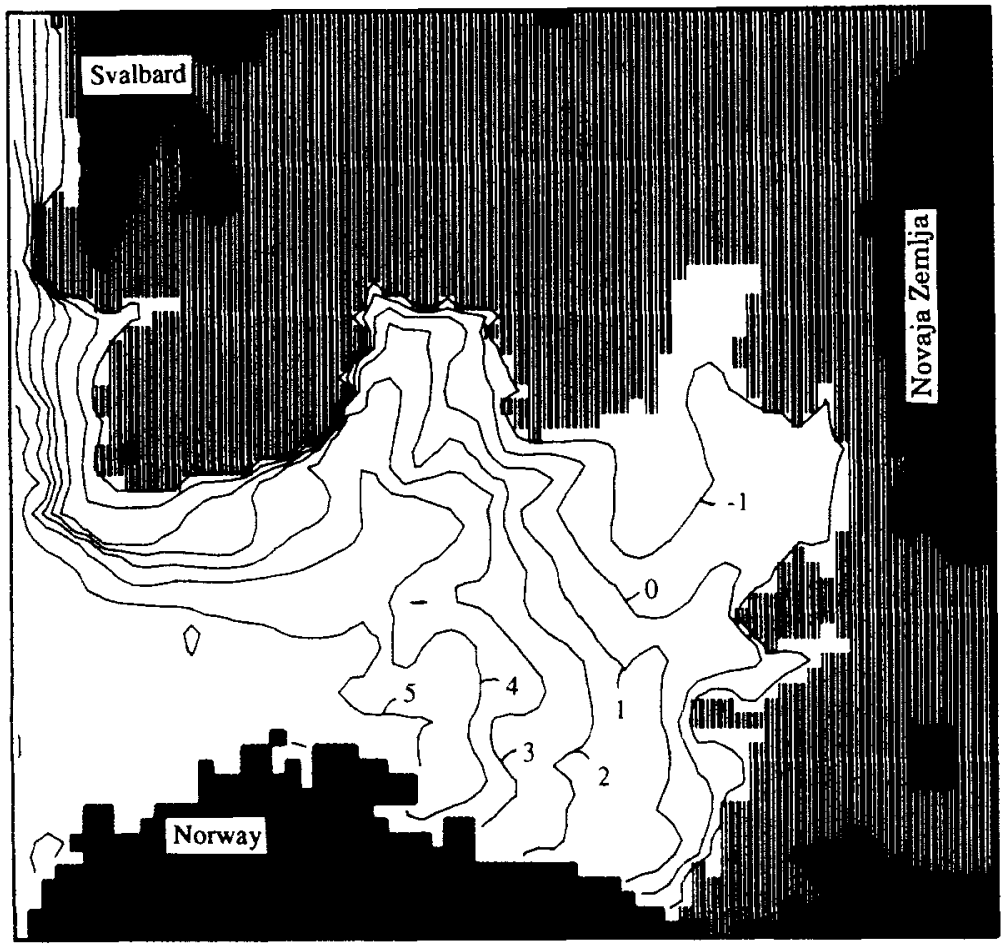

Fig. 4. Simulated ice distribution and surface temperature at the end of the "freezing" period.

3. For relative humidity, we set the values all over the area as equal to the Bjørnøya value.

Despite these adjustments, the atmospheric input still has different quality. But we are satisfied if it leads to results which give us "typical" current and density profiles.

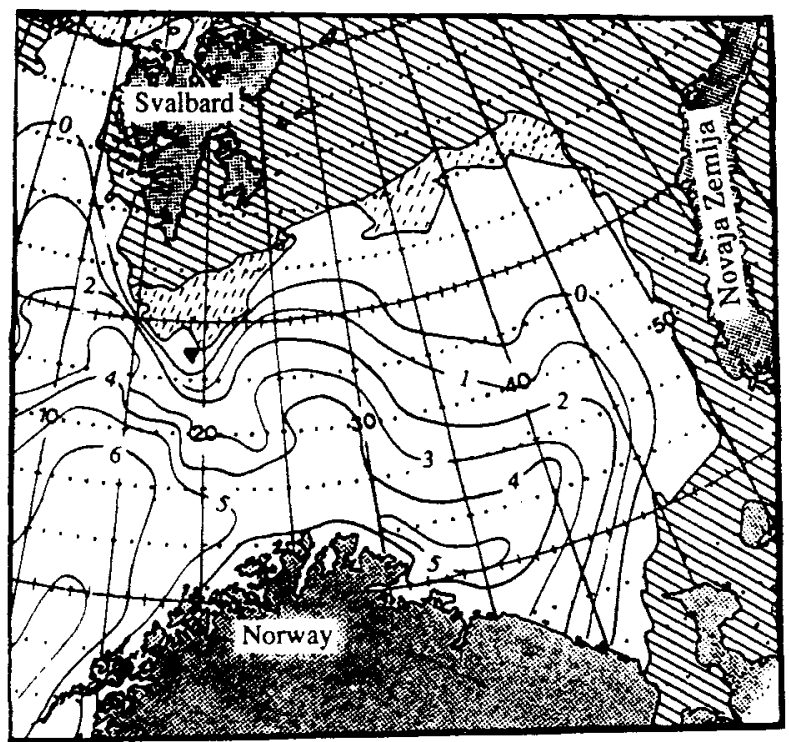

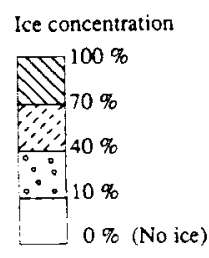

Fig. 5. Measured ice distribution and surface temperature (MI) from 14 February 1983. 


\section{Results}

\section{The "freezing" period}

The main purpose with the present hydrodynamical model is to simulate the physical environment and to use the data as input for a model of plankton growth (Slagstad \& StøleHansen 1991 this volume). The most active biological period is from March to mid-summer. As mentioned earlier, the purpose of the freezing period is to create a density field which is representative for an early spring situation. We start cooling from a measured density field from autumn 1988 (Slagstad et al. 1989).

To save computer time, the cooling was equated to a "severe winter day". The only atmospheric input was sensible heat flux. The temperature field was distributed in accordance with the description in the previous section. In the northeastern part, the air temperature was set at $-40^{\circ} \mathrm{C}$, increasing to $-20^{\circ} \mathrm{C}$ in the southwestern part of the model domain. After a few months with this input, the ice field shown in Fig. 4 was produced.

If the simulated ice cover and temperature field (Fig. 4) is compared with ice maps from MI, there seems to be quite a realistic distribution despite the simplified temperature input during the simulation period (for example the map from $14 \mathrm{Feb}$., 1983 shown in Fig. 5). The ice is situated in the north and east, and there are also tongues of ice towards Spitsbergenbanken and Sentralbanken. It is perhaps not surpising to see such a good correspondence because the ice is formed where the cooling is strongest (north and east) and where the energy content of the water column is lowest. Ice formation will therefore first take place in the water masses that were exposed to ice the previous year, in shallow areas such as the Spitsbergenbanken, and in the southeastern part of the Barents Sea. Wind and variable cooling, however, may change the ice distribution considerably from month to month and year to year (Vinje 1983; Loeng 1989).

The method used in this study to simulate an "early spring density field" is inconsistent and very simplified. A density field recorded in 1988 was used, a very cold and unrealistic temperature field with no wind as atmospheric input was applied, and finally the result was compared to data from 1983. The goal was to produce a density field that was typical for the area; with the accu-
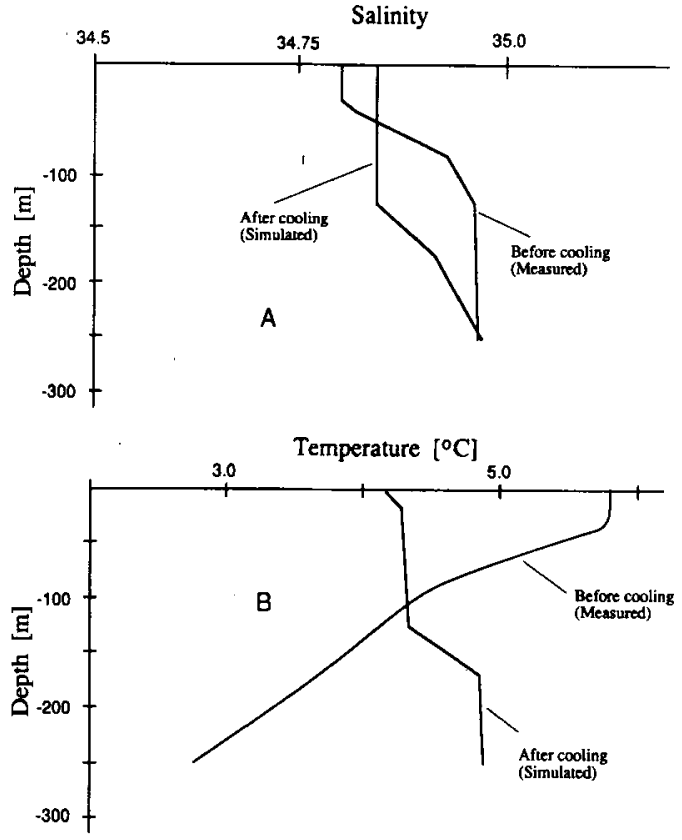

Fig. 6. Vertical profiles of (A) salinity and (B) temperature at station 1 , before and after the freezing period.
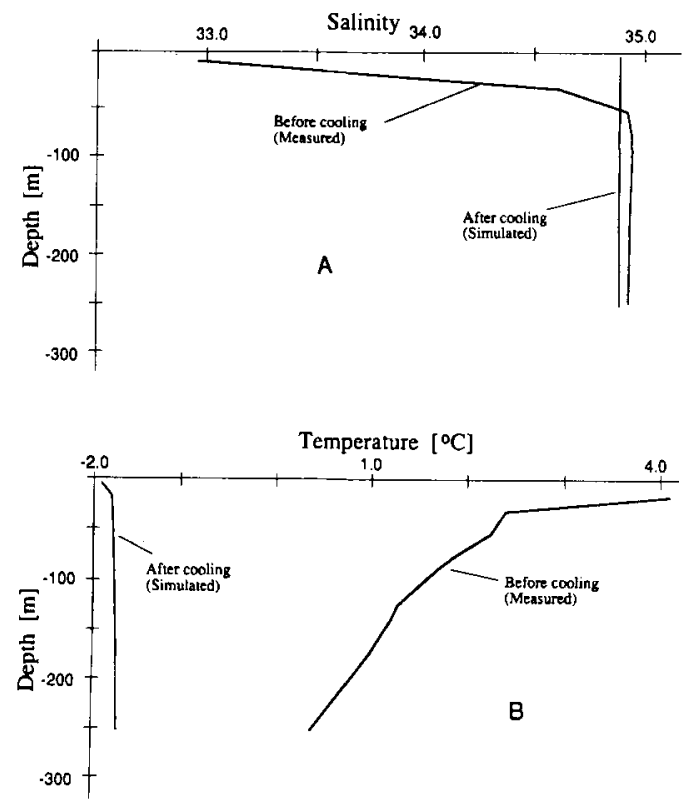

Fig. 7. Vertical profiles of (A) salinity and (B) temperature at station 2, before and after the freezing period. 
racy of the input data. 1988 or another year could be used for comparison.

Vertical profiles of temperature and salinity for two stations (see Fig. 2) are shown in Figs. 6 and 7. Before cooling. station 1 is dominated by waters with Atlantic origin, but this is probably mixed with coastal or melt water from ice in the upper $100 \mathrm{~m}$. The mixed depth is about $40 \mathrm{~m}$. After the cooling period there has been an increase in temperature near the bottom which is due to the advection of Atlantic Water from the southwest. The mixed depth is about 150 metres, a reasonable result according to Loeng (1989).

Station 2, which is on the southern slope of Storbanken, is also dominated by water of Atlantic origin before cooling, but there is a layer of melt water in the upper $40 \mathrm{~m}$. The mixed depth is $10 \mathrm{~m}$. During the cooling period. the stability of the whole water column is broken down (Fig. 7). At the end of the cooling the ice thickness at this station is about $1.5 \mathrm{~m}$. Further cooling would have increased the salinity due to brine rejection during the freezing process and probably contributed to the formation of bottom water (Midttun 1985).

One of the characteristic processes during sea ice formation is the release of salt to the surface laver. Fig. 8 shows the surface distribution of salinity on Spitsbergenbanken before and after the cooling period. Before the freezing period (Fig. 8A) there is water with low salinity on the bank and higher salinity outside, but at the end of the cooling period the opposite is the case (Fig. $8 \mathrm{~B})$. The surface salinity gradients are generally

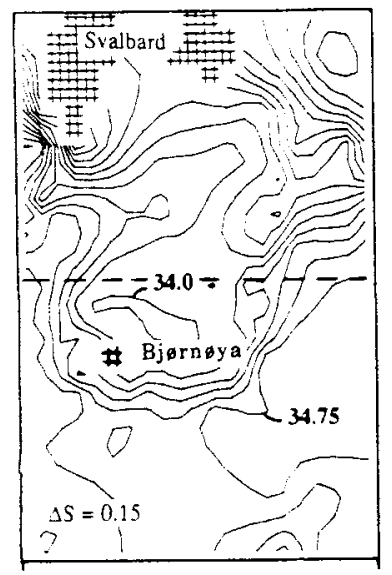

0

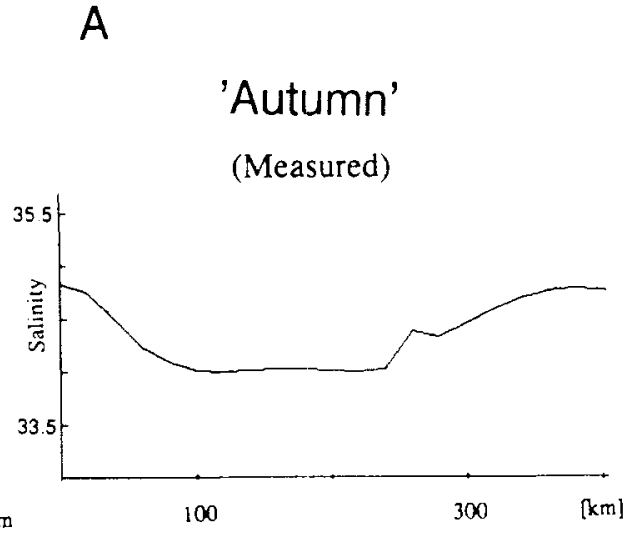

B

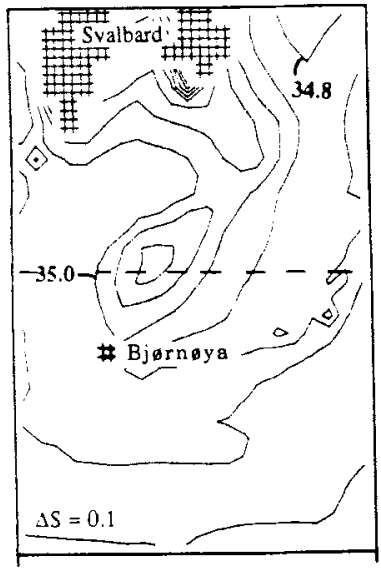

0
$400 \mathrm{~km}$

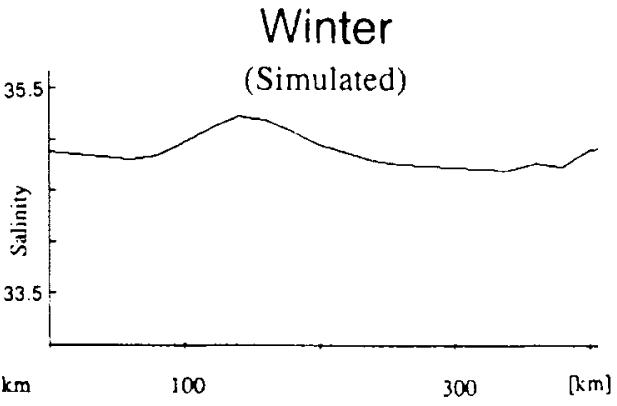

Fig. 8. Salinity field on Spitsbergenbanken before (A) and at the end (B) of the 'freezing' period. 
Fig. 9. Simulated ice distribution and surface temperature from 1 June 1983.

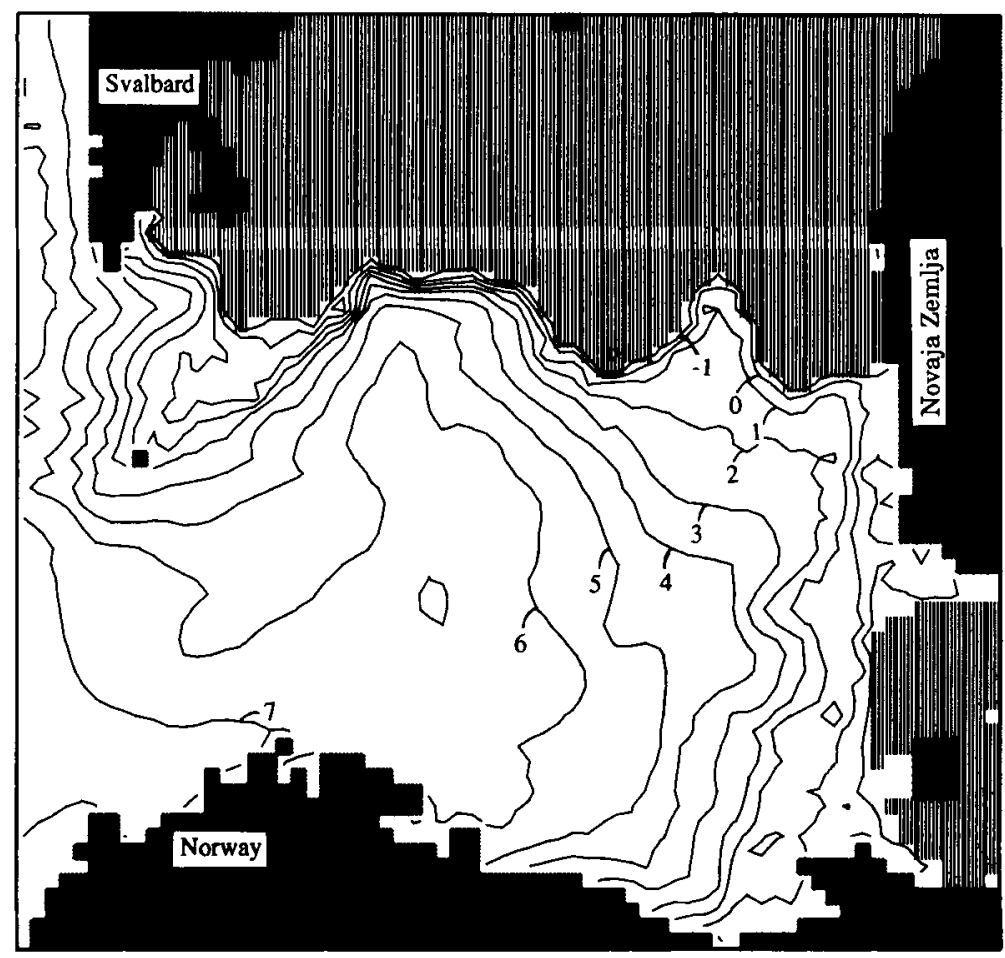

smaller after the freezing period. The profile of increased salinity on Spitsbergenbanken as shown in Fig. 8B has not been observed so far. This is probably because measurements have not been performed during the winter with an inconvenient heavy ice cover. However, dense bottom water (with salinity equal to 35.25 and temperature equal to $-1.9^{\circ} \mathrm{C}$ ) formed through brine rejection has been found in the Spitsbergenbanken area (Midttun 1985).

This is one of several structural changes in the density during the freezing period which should imply changes in the current patterns since the model is more or less density-driven when the wind stress is not applied. However, after cooling there are only minor changes in the current pattern compared to the field in Fig. 3.

\section{The "melting" period}

Initial values for the melting period are the simulated results from the freezing period, i.e. the current, ice, and density fields. But in this scenario we want to use more realistic atmospheric input than in the freezing period. Therefore, we have applied wind and pressure as well as a time series of air temperatures, solar radiaton, and relative humidity at Bjørnøya, as mentioned above in the "Input to the model" section.

The simulation started on 1 March 1983. At this time of year the solar radiation and air temperature were not able to melt the ice, which meant that we still were in a "winter situation". As was pointed out in the past section, our ice distribution from the freezing period had much in common with the MI ice map dated 14 Feb. 1983, only two weeks before our simulation started. We finished the simulation period on 31 July.

The entire year 1983 was warm with little ice and high water temperatures. The maximum ice extent was not much south of the ice border shown in Fig. 4 (Loeng 1989). During the spring, the southern limit of the ice did not change much until it began to retreat in June. Simulated ice distribution (Fig. 9) using the atmospheric input, described earlier in the "Input to the model" section, shows high correspondence with the observed map from the MI dated 6 June (Fig. $10)$. Both the model simulations and the measure- 


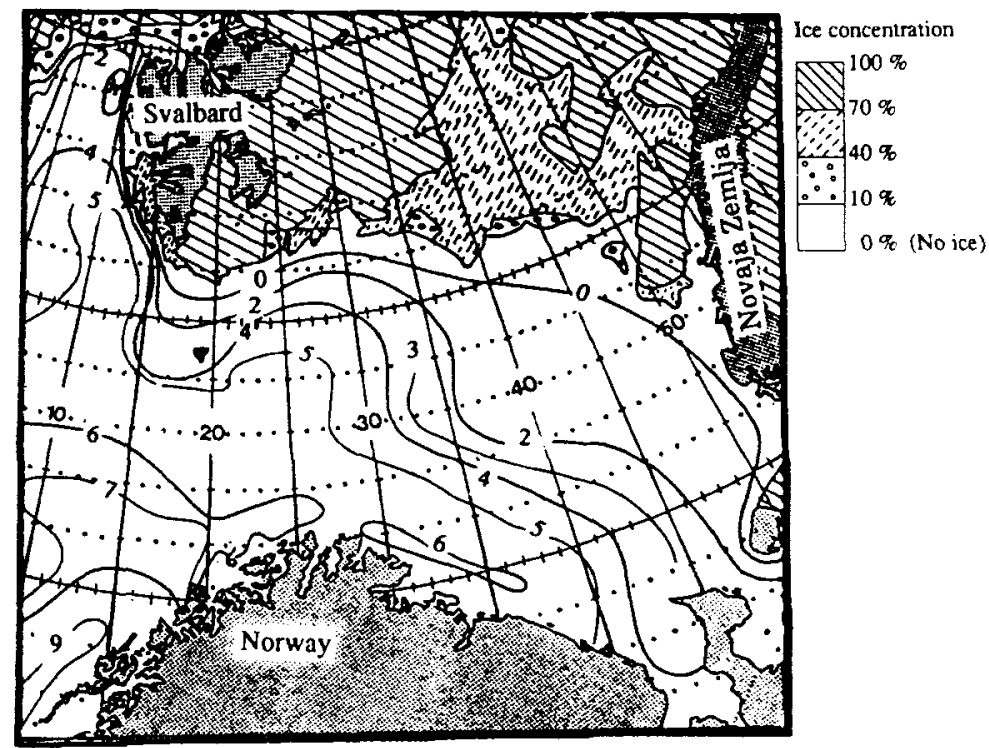

Fig. 10. Measured ice distribution and surface temperature (MI) from 6 Junc 1983.

ments show that the ice has retreated from the Spitsbergenbanken area and in the southeastern part of the model area.

The temperature time series in the seven uppermost levels of the model illustrate the variability in the vertical mixing (Fig. 11). The data are taken from station 1 (Fig. 2) which is situated in a region of Atlantic water masses. The upper part of the water column is well mixed until late May. Then, there is a rapid increase in temperature in the two uppermost model levels $(0-20 \mathrm{~m})$, indicating that a thermocline has been formed. This increase in temperature is interrupted by two mixing events in early June. These events were related to periods of high wind speed and were important for the transport of heat from the surface water downward in the water column. Temporal variability in vertical mixing, as described here, will affect the vertical transport of nutrients and thereby the primary production (Slagstad \& StøleHansen 1991). The formation of the thermocline was caused by the decreasing wind speed and an increasing rate of solar radiation at the end of May and early June.

A simulated south-north section (A-B in Fig. 2) of surface salinity at different dates is shown in Fig. 12. In the south, near the coast, there is a gradual decrease in salinity during spring due to river run-off. The melting of ice along this section starts in May and decreases the salinity near the ice border. During the following summer months more meltwater is released and horizontal diffusion and transport increases the area affected by melt ice.

A simulated salinity field in the Spitsbergenbanken area at the end of July is shown in Fig.

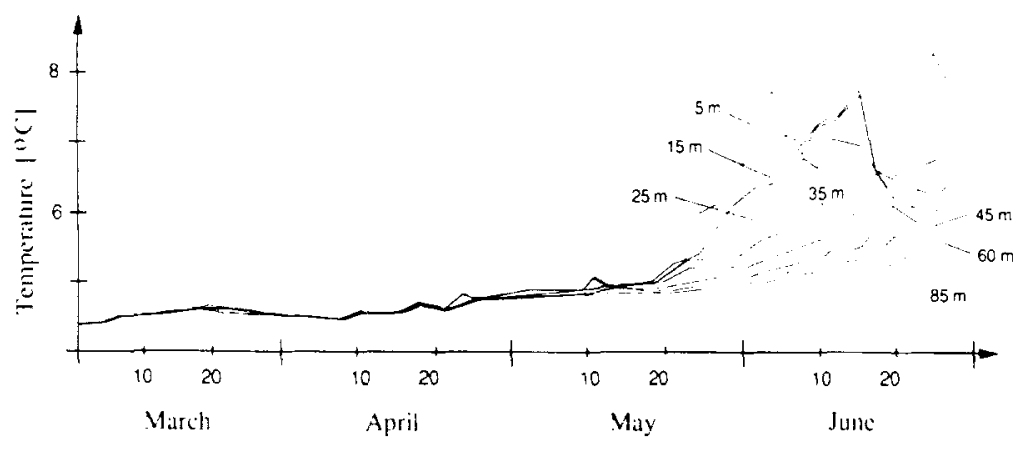

Fig. 11. Time series of temperatures in the 7 upper layers (i.e. $0-100 \mathrm{~m}$ ) of the water column at station 1 (Fig. 2). 
Fig. 12. Simulated southnorth surface salinity profiles at the end of April, May, June, and July along the section $\mathrm{A}-\mathrm{B}$ in Fig. 2.

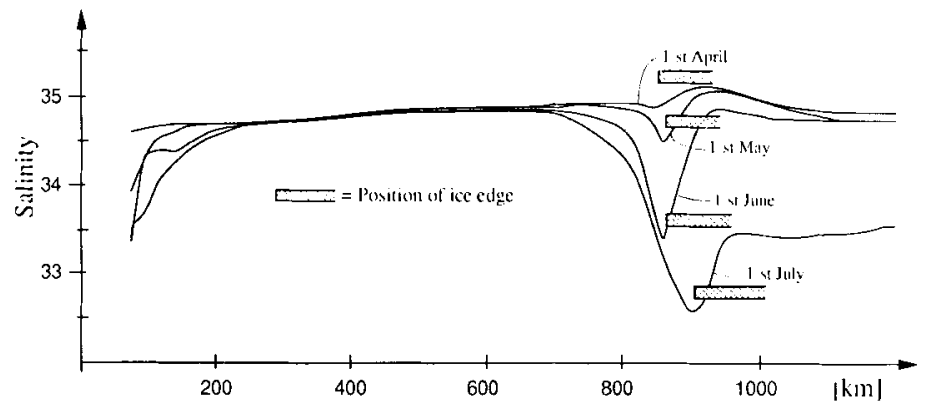

13. The salinity on the bank is much lower than the measured salinity 10 months earlier, and of that which is regarded as typical for the area during the summer period. This discrepancy is caused by strong tidal mixing breaking down the vertical stability over the shallow areas of the bank (Loeng 1989). Since there is no tidal input in the model, we obtain vertical stability and a surface layer dominated by meltwater on the bank. Vertical integrated salinity gives an average salinity of about 34.4 , which is typical for the area (Loeng 1989).

\section{Discussion and conclusions}

As was pointed out in the Introduction, this paper does not attempt to give a detailed reconstruction of the current fields and physics from the period we are simulating; rather it presents a study of the mechanisms concerning the melting/freezing of ice and vertical mixing in the water column. In other words, this study tests the model's capabilities of producing results that can be used as input to a biological model (Slagstad \& StøleHansen 1991).

One of the main aims of this test is to discover whether the model can actually produce density gradients and not annihilate them as time passes. Figs. 8 and 13 (surface salinity on Spitsbergenbanken) show that the model is capable of producing and maintaining such gradients during the different seasons. The two figures represent autumn, winter, and spring/summer and thereby a complete one-year cycle.

Another aim of importance is how the model handles the freezing of ice, and whether the different density gradients appear geographically in the correct position. The latter property is of course highly dependent on the distribution of the ice cover. We observed that the ice cover that was produced in general accorded well with the
Fig. 13. Salinity ficld on Spitsbergenbanken at the end of the "melting pcriod".

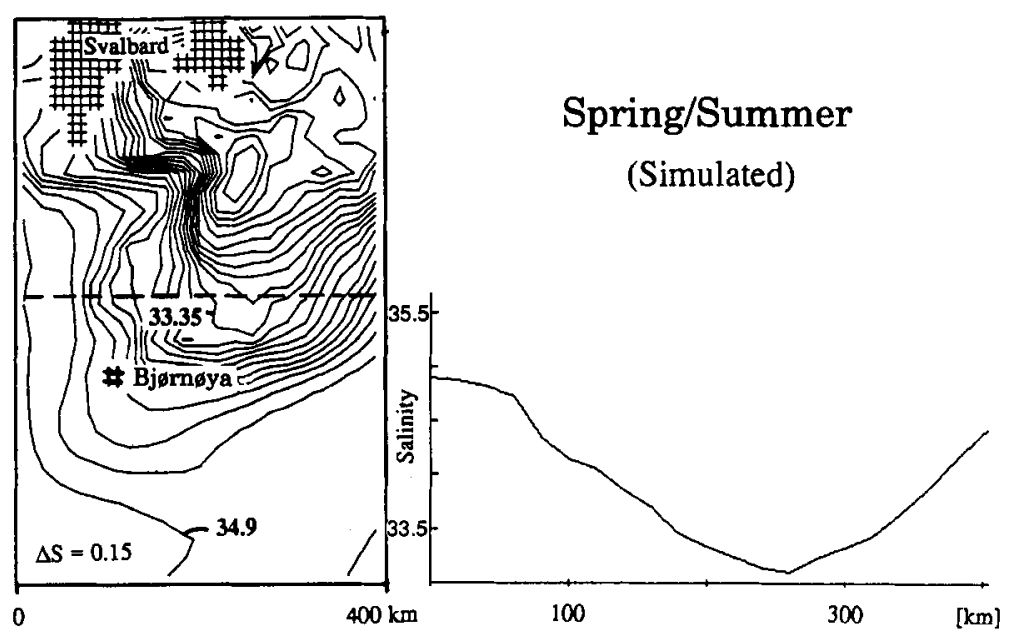


observed ice maps. This was surprising considering the highly simplified energy input.

Examination of the vertical profiles of temperature and salinity (Figs. 6 and 7) reveals that they seem to be typical compared to what is observed (and assumed). In the Atlantic Water the mixed layer is about 30-40 metres before cooling (autumn) and 100-150 metres after the cooling (winter). In the Arctic waters the mixed layer is more shallow before the cooling, but deeper (almost permeating the entire water column) after the cooling.

The time series of temperature has been plotted in several levels down to $100 \mathrm{~m}$ (Fig. 11). Station 1 is situated in typical Atlantic waters, and it is difficult to compare this data series to real data since there are no measured data with this form and resolution. Nevertheless, the time series indicates that the mixed layer depth can vary to a greater extent during a rather limited period of time. Our simulation results show variations in the mixed layer depth from 10 to almost 100 metres in June. This will certainly have a great impact on the primary production (Slagstad \& Støle-Hansen 1991).

Our conclusions give a brief summary of our findings:

1. The current field produced by simulation is similar to what is observed, especially in the southern part of the area; using these data as a basis for this study, our findings agree with those from earlier studies (Slagstad 1987; Slagstad et al. 1989).

2. The ice cover and the processes of freezing and melting of ice in our model develop geographically in a realistic way.

3. The physical processes that are represented in the model seem to be able to maintain density gradients over a long time scale (monthsyear), despite the numerical diffusion of this kind of model.

4. The vertical mixing seems to respond realistically to various wind stresses, freezing and cooling, and vertical density distributions. Thus, because of its importance for biology. this is probably the part of the model that should be improved first.

Acknowledgements. - This work is part of the Norwegian Research Program for Marinc Arctic Ecology (Pro Marc) and was financed by the Norwegian Fisheries Research Council.

\section{References}

Adlandsvik. B. 1989: Wind-driven variations in the Atlantic inflow to the Barents Sea. ICES Paper CM $1989 / \mathrm{C}: 18$. p. 13.

Aagaard, K.. Foldvik, A. Gammelsrød. T. \& Vinje, T. 1983: One sear records of current and hottom pressure in the strait between Nordaustlandet and Kvitøya. Svalbard, 1980-81. Polar Res. 1, 107-113

Berntsen. H. Kowalik. Z.. Salid, S. \& Sorli. K. 1981: Efficient numerical simulation of ocean hydrodynamics by a splitting procedure. Modelling, Identification and Control 2, 181-199.

Blindheim. J. 1989: Cascading of Barents Sea Bottom Water into the Norwegian Sea. Rapp. P.-v. Réun. Cons. Int. Explor. Mer $188.49-58$.

Hibler. W. D. 1979: A dynamic thermodynamic sea ice model. J. Phys. Oceanogr. 9.815-846.

Loeng. H. 1989: Ecological features of the Barents Sea. Pp 327-365 in Rey. L. and Alexander. V. (eds.): Proc. 6th Conf. Com. Arctic. Internatl. 13-15 Moy 1985. E. J. Brill. Leiden.

Mesinger. F. \& Arakawa, A. 1976: Numerical methods used in atmospheric models. GARP Publ. Ser. WMO 17.64 pp.

Midttun, L. 1985: Formation of dense bottom water in the Barents Sea. Deep-Sea Res. 32, 1233-1241.

Midtun, L. \& Loeng. H. 1987: Climatic variations in the Barents Sea. Pp. 13-27 in Loeng, H. (ed.): The effect of oceanographic conditions on distribution and population dynamics of commercial fish stocks in the Barents Sea. Proc. 3rd Soviet-Norwegian Symp.. Murmansk, 26-28 May 1986. Inst. of Mar. Res.. Bergen, Norway.

Orlanski. 1. 1976. A simple boundary condition for unbounded hyperbolic flows. J. Comput. Phys. 21, 251-269.

Pollard. M. Batteen. M. L. \& Han, Y-J. 1983: Development of a simple upper-ocean and sea-ice model. J. Phys. Oceanogr. 13. 754-768.

Price. J. F. \& Weller. A. 1986: Observations and Models of the Upper Ocean Response to Diurnal Heating, Cooling, and Wind Mixing. J. Geophys. Res. 91, 8411-8427.

Rodi. W. 1987: Examples of calculation methods for flow and mixing in stratified fluids. J. Geophys. Res. 92, 5305-5328.

Slagstad. D. 1987: A 4-dimensional physical model of the Barents Sea. SINTEF Rep. STF48 F87013, 1-34, Trondheim.

Slagstad. D. Støle-Hansen, K. \& Loeng. H. 1989: Densitydriven currents in the Barents Sea calculated by a numerical model. ICES Paper CM 1989/C: 20.14 pp.

Slagstad, D. \& Støle-Hansen, K. 1991: Dynamics of plankton growth in the Barents Sea. Model studies. Pp. 173-186 in Sakshaug. E., Hopkins. C. C. E. \& Oritsland. N. A. (eds.): Proceedings of the Pro Mare Symposium on Polar Marine Ecology. Trondheim, 12-16 May 1991. Polar Research 10(1).

Tingelc. A. Dieterle. D. A. \& Walsh. J. J. 1979: Perturbation analysis of the New York Bight. Pp. 395-435 in Livingston. R. J. (ed.). Ecological Processes in coastal and marine systems, Plenum Press. New York.

Vinje, T. E. 1983: Sea ice conditions in 1982. Norsk Polar Inst. Árbok 1982, 49-53

Tantsiura. A. I. 1959: About the current in the Barents Sea. Trudy Polyar. Nauchno-issled. Inst. Morsk. Ryb. Khoz. Okeanol. 11. 35-53 (in Russian).

Zubov. N. N. 1945: L'dy Arktiki (Arctic Ice). Izdatel'stvo Glauseumorputi, Moscow. 360 pp. 